\title{
Learning from international internships
}

\section{Niemantsverdriet S. Learning form international internships. A reconstruction in the medical domain. Universiteit Maastricht, 26 juni 2007. Promotoren: prof. dr.C.P. van der Vleuten en prof. dr. A.J.J.A. Scherpbier; co-promotor: dr G.D. Majoor. 125 pagina's. ISBN 9789052786292}

In het kielzog van historische en politieke ontwikkelingen, zoals globalisering, Europeanisering en het Bolognaproces, kwam in het medisch onderwijs aandacht voor internationalisering. In de medisch onderwijskundige literatuur werd echter niet veel gepubliceerd over internationalisering van het onderwijs. De schaarse studies die er waren lieten niet toe er robuuste conclusies uit te trekken; dit vanwege de methodologische beperkingen van deze studies. Het was ook niet duidelijk hoe en of hedendaagse onderwijskundige theorieën over leren in de (klinische) werkplaats toegepast konden worden op de internationalisering van het medisch onderwijs. Dit bracht ons ertoe een brede algemene onderzoeksvraag te formuleren als richtsnoer voor het onderzoek:

'Wat zijn de opleidingseffecten van internationalisering van de opleiding voor het leren in de medische basisopleiding?'

Om deze algemene onderzoeksvraag te beantwoorden zijn meer specifieke onderzoeksvragen geformuleerd. Deze specifieke onderzoeksvragen zijn gebaseerd op de achtereenvolgende bevindingen uit de studies, die tezamen dit proefschrift vormen. Zo is bijvoorbeeld na beantwoording van de eerste specifieke onderzoeksvraag besloten de overige vragen te richten op buitenlandse stages. Dit vanwege het gegeven dat de buitenlandse stage op dat moment in Nederland de meest

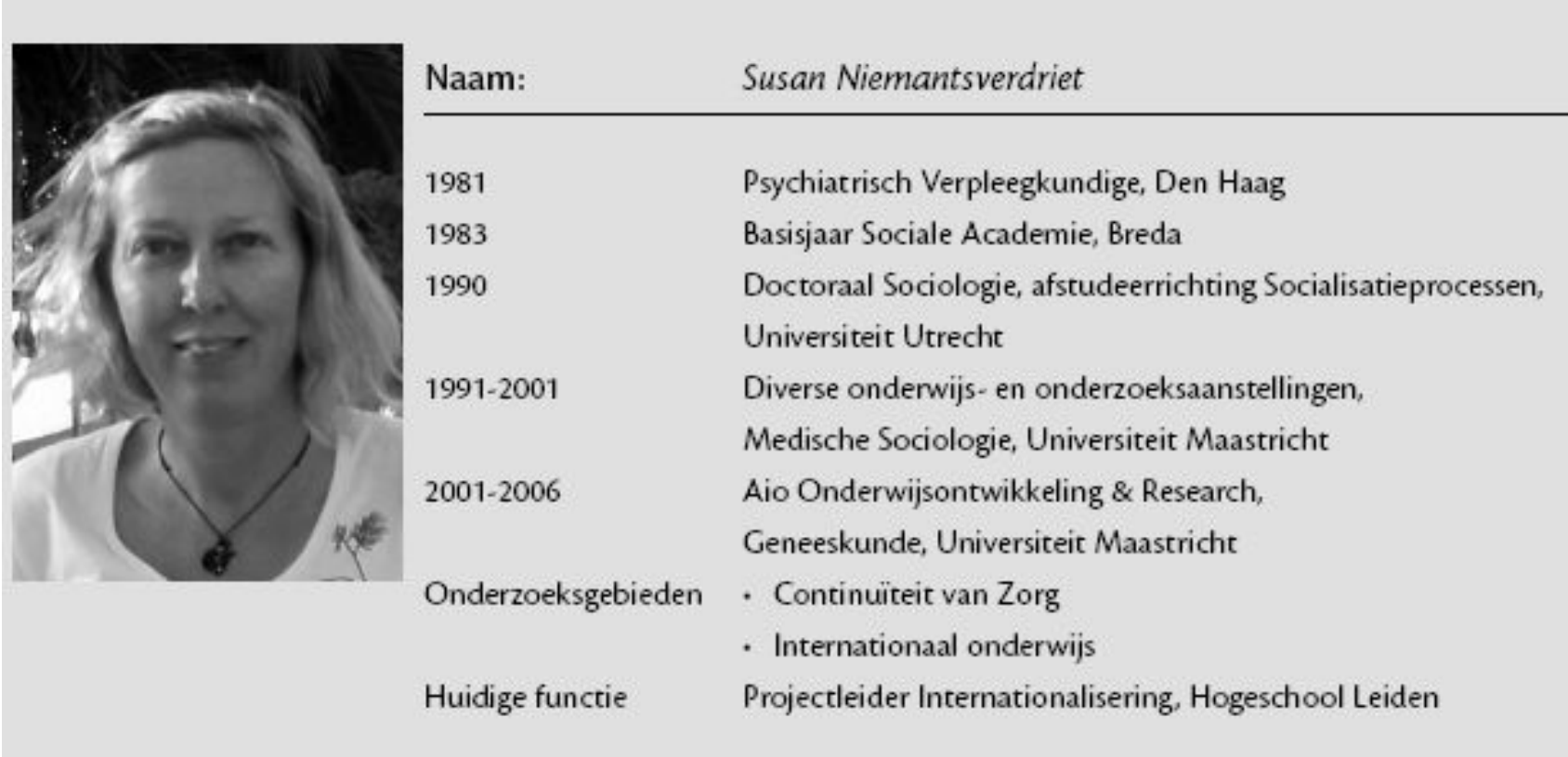


voorkomende vorm van internationalisering van het medisch onderwijs was.

De specifieke onderzoeksvragen zijn:

1. Welke aspecten van internationalisering kunnen worden onderscheiden in de Nederlandse curricula geneeskunde?

2. Wat leren studenten geneeskunde in de basisopleiding van buitenlandse stages?

3. Wat is de aard van het leerproces wanneer studenten geneeskunde in de basisopleiding op een buitenlandse stage gaan?

4. Beïnvloeden sociaal-culturele verschillen de aard van het leerproces wanneer studenten geneeskunde uit de basisopleiding op een buitenlandse stage gaan?

5. Wat zouden de leeruitkomsten moeten zijn van buitenlandse stages van studenten geneeskunde in de basisopleiding?

De aard van de onderzoeksmethodologie die gehanteerd is bij de verschillende studies, die tezamen het proefschrift vormen, kan gekarakteriseerd worden als 'Grounded Theory'. Dit is een onderzoeksmethode die vooral, maar niet uitsluitend gebruik maakt van kwalitatieve onderzoekstechnieken. Er zijn verschillende manieren gebruikt om data te verzamelen, zoals een elektronische vragenlijst en diepte-interviews. De elektronische vragenlijst werd ingevuld door zeven (van de acht) coördinatoren die zich in de Nederlandse opleidingen geneeskunde bezighouden met Internationalisering. Diepteinterviews werden met 24 studenten van de basisopleiding geneeskunde in Maastricht gehouden en met 17 buitenlandse begeleiders van Nederlandse studenten geneeskunde in Australië. Tenslotte is een internationale groep experts op het gebied van internationalisering geraadpleegd met behulp van een elektronische vragenlijst (ronde $1 \mathrm{n}=55$; ronde $2 \mathrm{n}=36$ ).

Als antwoord op de algemene onderzoeksvraag werd geconcludeerd: leren van buitenlandse stages is in potentie leren in een krachtige leeromgeving, waar studenten nieuwe kennis, vaardigheden en attitudes kunnen verwerven in een context met authentieke complexe taken. De brede reeks van de door de studenten gerapporteerde leeruitkomsten omvat gewenste leeruitkomsten van de medische basisopleiding.

Het bleek mogelijk de onderzoeksresultaten in te passen binnen de onderwijskundige theorieën over het 'nieuwe leren', zoals beschreven door Simons ${ }^{1}$ en binnen het 'leren in context', zoals beschreven door Volet, ${ }^{2}$ en binnen het 'leren in de klinische werkplaats thuis', zoals beschreven door Dornan. ${ }^{3}$

In het laatste hoofdstuk van het proefschrift wordt een inleidende 'Grounded Theory' over leren in buitenlandse stages geformuleerd. De kerncategorie in de geformuleerde 'Grounded Theory' voor productief leren in buitenlandse stages, is het gevoel 'erbij te horen' op de stageplaats.

Naar aanleiding van onze onderzoeksresultaten en conclusies bevelen we aan het leren van buitenlandse stages nog productiever te maken, met name door het gevoel 'erbij te horen' van de student op de buitenlandse stageplaats te vergroten. Om dit te bereiken raden we aan meer structuur te brengen in de leerprocessen van de studenten door: uitbreiden van 'zelf-gestuurd leren', gebruik te maken van 'independent work', uitbreiden van 'geleide leerprocessen' en door het trainen van copingstijlen van studenten.

In vervolgonderzoek zou de hierboven aangegeven aanbevelingen voor de praktijk geëvalueerd kunnen worden. Verder zou vervolgonderzoek zich kunnen richten op het exploreren van mogelijkheden om het leren van studenten in buitenlandse stages te beoordelen. Het is ook interessant te onderzoeken hoe deze beoordelingen een rol zouden kunnen spelen in kwaliteitszorg.

Daar het in dit proefschrift beschreven onderzoek zich geconcentreerd heeft op buitenlandse stages, kunnen we slechts een deel van de algemene onderzoeksvraag beantwoorden. Bij de start van ons onderzoek, begin 2000, was de buitenlandse stage de meest voorkomende vorm van internationalisering van medisch onderwijs. Gedurende de looptijd van het onderzoek zijn ook andersoortige vormen van internationalisering verder op gang gekomen. Daarom bevelen we ook aan vervolgonderzoek te richten op 'Internationalisation at Home', met inbegrip van inwaarts gerichte mobiliteit.

Ondanks onze pogingen de kwaliteit van de onderzoeksmethodologie en de onderzoeksbevindingen te waarborgen zijn er toch beperkingen aan de conclusies uit dit kleinschalige onderzoek. We bevelen daarom aan de hier gepresenteerde bevindingen te testen in representatieve steekproeven in verschillende nationale culturele contexten.

\section{Literatuur}

Simons PRJ, Linden J van der, Duffy T. New learning: three ways to learn in a new balance. In: Simons PRJ, Linden $\mathbf{J}$ van der, Duffy T (Eds). New learning. Dordrecht: Kluwer Academic Publishers; 2000.

Volet SE. Learning and motivation in context: A multi-dimensional and multi-level cognitivesituative perspective. In: Volet SE, Järvelä S (Eds). Motivation in learning contexts: Theoretical advances and methodological implications. London: Elsevier; 2001.

Dornan T. Experience based learning. Learning clinical medicine in workplaces [dissertatie]. Maastricht: Datawyse; 2006. 